IJBPAS, May, 2021, 10(5): 1652-1659

ISSN: 2277-4998

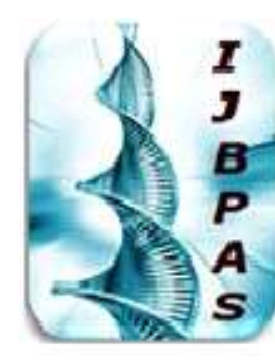

International Journal of Biology, Pharmacy

and Allied Seiences (IJBPAS)

'A Bridge Betusen Caboratory and Q Qundo'

WwW.ijbpas.com

\title{
ISOLATION AND CHARACTERIZATION OF HEAVY METAL \\ RESISTANT FUNGAL ISOLATES FROM FOUNDRY SOIL SAMPLES IN \\ COIMBATORE, TAMILNADU, INDIA
}

\section{N. GUNASHEELA ${ }^{1}$ AND HEMA SHENPAGAM $\mathbf{N}^{2 *}$}

1: Assistant Professor, Department of Microbiology, Sri Ramakrishna College of Arts and

Science for Women, Coimbatore, Tamilnadu, India

2: PG Head \& Associate Professor, Department of Microbiology, Hindusthan College of Arts and Science, Coimbatore, Tamilnadu, India

*Corresponding Author: N. Hema Shenpagam: drhemashenbagam@gmail.com

Received $16^{\text {th }}$ June 2020; Revised $17^{\text {th }}$ July 2020; Accepted $14^{\text {th }}$ Aug. 2020; Available online $1^{\text {st }}$ May 2021

https://doi.org/10.31032/IJBPAS/2021/10.5.5479

ABSTRACT

In the last few decades, heavy metals pollution has become a serious environmental problem. The potential technology needs to be developed that can remove toxic metals found in contaminated environments. In this present study, foundry soil samples were collected and isolate the various fungal genera. This study was undertaken to determine the resistance levels of different concentrations of heavy metals (lead and zinc) using filamentous fungi of Neurospora spp and A.terrus. Based on the results, the A.terrus gave the highest tolerance ability of zinc $(4.5 \mathrm{mM})$ and lead $(3 \mathrm{mM})$. Those cultures were further checked for their potential to produce organic acid. Furthermore, the potential isolate was subjected to molecular characterization of $18 \mathrm{~S}$ rRNA for confirmation, according to blast analysis, which isolate was A.terrus. The present study shows that heavy metals contaminated foundry soil can be considered a valuable natural source of resistance isolates, which can be used significantly as bioremediation techniques.

Keywords: Foundry soil, Lead, Zinc, A.terrus, Organic acid 


\section{INTRODUCTION}

The spread of heavy metals in the terrestrial surrounding is generally attributable to anthropogenic activities such as field application of sewage sludge, a number of industrial activities and disposal of waste products. Among the different pollutants, heavy metal was important pollutants and persistent in the soil environment. Waste foundry sand (WFS) is one of such industrial by-product or considered as waste discarded material coming from ferrous and nonferrous metalcasting industry. Heavy metals are common environmental pollutants that are released in WFS as a result of casting in metal foundries. These include chromium, cadmium, mercury, lead, nickel, arsenic and silver [1]. These heavy metals, as well as their compounds, are toxic to living organisms.

Waste foundry sands are really the highest volume of solid waste produced by foundries. The high landfilling expenses and potential uses of waste foundry sand for construction purpose have contributed to research into their beneficial reuse. With increased restrictions, industries are constrained to find alternative ways to reuse waste. Nowadays, the use of microorganisms for recycling of foundry sand is increasing. Microorganisms have been proven to possess the ability to survive via adapting or mutating at excessive concentrations of heavy metals [2].

Fungi are pervasive in the natural env ironment and are identified as more than 70,0 00 species of fungi. Some estimates suggest that 1.5 million species may exist [3]. The filamentous fungi isolated from heavy metal contaminated soil such as Aspergillus spp and Penicillium spp has a high level of resistance to a number of metals [4].

Generally, fungi have often been proposed as bioagents for metal recovery processes. This study was carried out to isolate fungi from metal contaminated sites of the foundry industry and evaluate their resistance level. Those fungal isolates may also possess positive survival mechanisms due to their highly contaminated habitat, which may make them much more significant to be used as a bioremediation process.

\section{METHODOLOGY}

\section{Sample collection}

Foundry soil sample were collected in sterilized bags from the dumped site of a local foundry located at Coimbatore (Tamilnadu, India). Sieve analysis of all fine aggregates \& coarse aggregate was carried in the laboratory. 


\section{Isolation of fungi}

The soil samples were collected for the isolation of fungi. One gram was transferred to aliquots of $9 \mathrm{~mL}$ sterile distilled water in a test tube. It was shaken vigorously at a constant speed for $15 \mathrm{~min}$ and plated onto Potato Dextrose Agar (Hi media). The soil suspension was then subjected to serial dilutions up to $10^{-6}$. After sterilization, the medium was supplemented with $30 \mu \mathrm{g}$ streptomycin/ml (Himedia, Mumbai, India) to inhibit bacterial contamination. The medium was incubated at $35{ }^{\circ} \mathrm{C}$ for $72 \mathrm{~h}$. The pure colonies were isolated by subculturing on PDA. Stock cultures were maintained at $4^{\circ} \mathrm{C}$. Colonies having zone formation were subcultured in potato dextrose broth. The spore morphology was determined by light microscopy [5].

\section{Screening for Metal Resistance}

All the fungal isolates were evaluated for their metal resistance against varying concentrations of heavy metals that included zinc as $\mathrm{ZnSO} 4$ and lead as $\mathrm{Pb}\left(\mathrm{NO}_{3}\right)_{2}$ [6]. The metal tolerance assay was carried out for the fungal isolates through agar plate method. For each metal, separated plates were used. The tolerance assays was determined by the plate dilution method against metal by gradually increasing its concentration in SDA media. The initial concentration used was
$1 \mathrm{mM} / 20 \mathrm{ml}$ with a gradual increase until the isolates failed to give colonies on the plate, which was $15 \mathrm{mM} / 20 \mathrm{ml}$. The highest concentration that prevented fungal growth was considered as tolerant for that isolate.

\section{Isolation of organic acid producing isolates}

The isolated cultures were subjected for the screening of organic acid production by plate method [7] with slight modifications. The positive results were indicated by yellow colour formation around the mycelia growth. The potential isolates were subjected to determinate the biomass on PDA media [8].

\section{Molecular identification}

The total genomic DNA of the fungal isolates were isolated and purified by using the methods as described by [9]. The common primers for amplification and sequencing of internal transcribed spacer (of (ITS) from the fungal strains were performed.

\section{Phylogenetic analysis}

The sequences obtained and were aligned by using BLAST analysis (http://www.ncbi.nlm.nih.gov/BLAST), for comparison with currently available sequences. The sequences which showed over $99 \%$ or above resemblance or similarities with currently accessible sequences were regarded as to be the same 
species. Furthermore, multiple alignments were performed using Clustal $\mathrm{W}$, and MEGA7 is used for the constructing phylogenetic tree [10].

\section{RESULTS AND DISCUSSION}

All soil samples were analyzed for physiochemical properties $(\mathrm{pH}$ and moisture). All samples had above $\mathrm{pH} 7$; the $\mathrm{pH}$ was ranged from 7.3 to 10.7 . Among the 34 samples, single soil samples had the highest $\mathrm{pH}$ value (10.7). Most of the soil samples have been showed $\mathrm{pH} 8$ or above. This might be attributed to the addition of alkaline earth metals like $\mathrm{Ca}, \mathrm{Mg}$ and alkali metals like $\mathrm{Na}$. The soil moisture was analysis for all samples. The highest moisture values were noticed in a single sample, which was showing $10 \%$ of moisture. The range of the moisture was $0.20 \%$ to $10 \%$.

Metal tolerance is defined as the capability of an organism to survive in response to metal. The biological mechanism involved in fungal survival in metal polluted soil samples and aqueous solution includes extracellular precipitation, crystallization, a transformation of metals, biosorption of cell wall, decreased transport or impermeability, efflux, intracellular compartmentation and sequestration [11].
Prolonged exposure of soil fungi to high doses of heavy metals has developed resistance in them [12]. In the present study, a total of 67 soil fungi were isolated from the heavy metal contaminated soils. On the basis of morphological characterization, totally 11 fungal genera were observed, namely Colletotrichum spp, Rhizopus, Neurospora spp, Absidiya spp, Penicillium spp, Mucor, A.terrus, Aspergillus spp, Trichoderma spp, A.niger, Yeast and unknown. Among them Neurospora spp (41.1\%) was highest predominant and second most was A.terrus (26.4\%) and followed by Mucor (23.5\%), and lowest prevalence was yeast (3\%) (Figure 1 and 2).

The occurrence of these genera in heavy metal-polluted soil has been reported in different parts of India. In 2014, Raman et al., [13] were observed the various genera of fungal isolates from metal containing soil samples. The results of research on the fungal isolates taken from the foundry soil sand are very low. Asokan et al., [2] were observed the $R$. oryzae from foundry waste sand from Coimbatore area, Tamilnadu.

Fungi are a versatile group as they can adapt and grow under various extreme conditions of $\mathrm{pH}$, temperature and nutrient availability as well as at high metal concentrations [8]. They can change or 
reduce the toxicity of metallic contaminants through organic acid, $\mathrm{pH}$ change, biosorption and bioaccumulation. In this current study, predominant isolates of Neurospora spp and A.terrus were subjected to metal tolerance assays. For this test, two metals were utilized namely zinc and lead. Among the different concentration of metals, all isolates of Neurospora spp were grown up to $1 \mathrm{mM}$ of both metals. In case of A.terrus, two isolates (S17 and S19) were grown up to $4.5 \mathrm{mM}$ concentration of zinc. While using lead, same isolates were grown up to $3 \mathrm{mM}$ concentration of lead.

In 2014, Sharma et al [14] were observed the zinc resistance Aspergillus sp from metal contaminated soil samples, which was grown up to $15 \mathrm{mM}$ concentration. Zinc and lead is essential for all microbes; however, at higher concentrations, it can be toxic. The fungal colour and morphology were both affected by high $\mathrm{Zn}$ concentrations as observed by Balsalobre et al [15].

From the overall studies, the highest metal resistance capacity was observed from A.terrus, which was selected for further study. The growth of A.terrus tested was found decreased after addition of lead in high concentration in comparison with zinc. In 2015, Gayathri et al (16) were observed the Aspergillus and Pencillium from metal containing foundry soil samples. Another hand of Asokan et al. 2016 reported that the microbial treatment of waste foundry sand was analyzed for its metal leachate property. Recently, Padmasini and Vijayakumari [17] were bioleaching the industrial waste foundry sand by Aspergillus sp. treated as biofertilizer for the growth of herbal plants.

A series of organic acids are formed by fungal as well as bacterial metabolism resulting in organic acidolysis, complex and chelate formation. In the present study, metal resistance isolates of A.terrus were subjected to organic acid production. Among the 9 isolates, 4 of were producers for organic acid production.

According to biomass production, S19 isolate was fast growth highly produce the biomass than $\mathrm{S} 17$ isolate, this isolate was produce the organic acid also, hence, isolate S19 was subjected to 18srRNA sequence analysis. The NCBI database and Phylogenetic analysis was confirmed that isolate as Aspergillus terrus. Based on the BLAST analysis on similarity, the result of isolates of 18S rRNA sequence with gene bank it was found that the fungal isolate designated as S19 has 99\% similarity with Aspergillus terrus (Figure 3). 


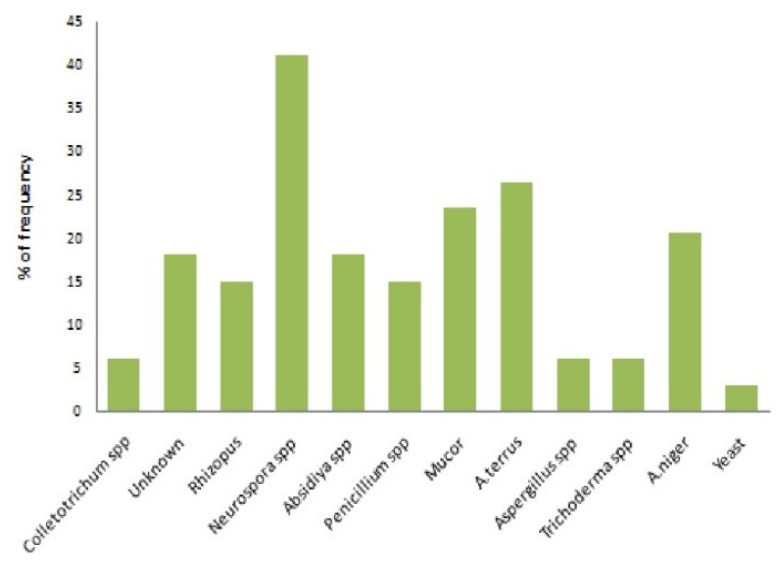

Figure 1: Frequency of fungal isolates on foundry soil samples

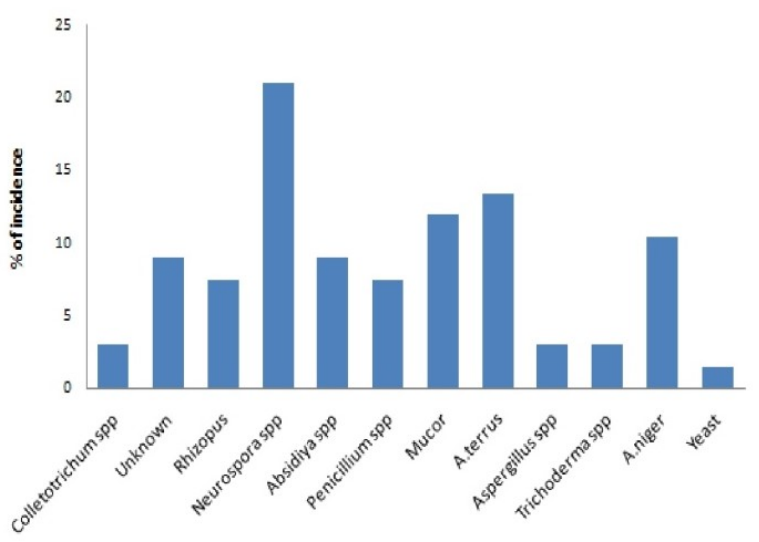

Figure 2: Incidence of fungal isolates on foundry soil samples

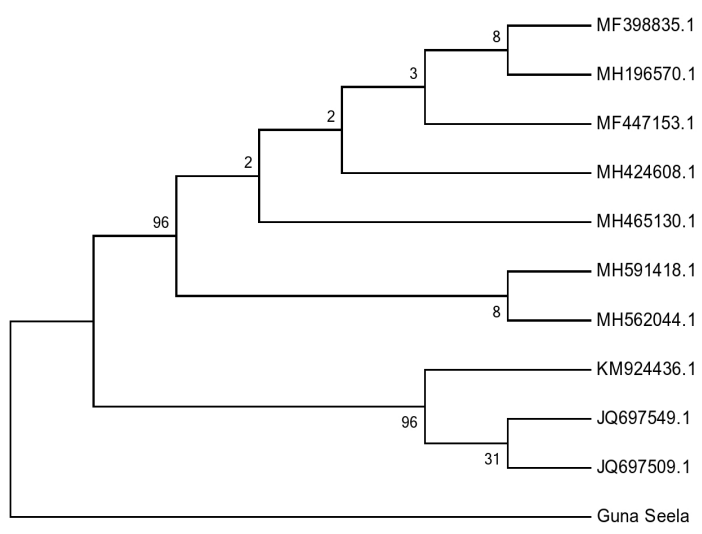

Figure 3: Phylogenic tree of Aspergillus terrus

\section{CONCLUSION}

Our findings indicate that fungal populations isolated from metal contaminated foundry sand sites have the ability to resist higher concentrations of trace metals like Zinc and lead. The isolated isolate of Aspergillus terrus was the most tolerant to two metals tested which makes them promising isolates to further investigate their ability to remove metals from contaminated environment and can be used as agents for bioremediation.

\section{REFERENCE}

[1] Ji S et al., The toxic compounds and leaching characteristics of spent foundry sands. Water Air and Soil Pollution. 132; 2000: 347-364.

[2] Asokan $\mathrm{P}$ et al., Treatment of Waste Foundry Sand Using Fungi: An Approach for the Application in Manufacture of Concrete. International Journal of Applied Engineering Research. 11(3); 2016: 1849-1853.

[3] Hawksworth DL and Mueller GM. Fungal communities: their diversity and distribution. In: Dighton J, Oudemans P, White J (eds.). The fungal community: its organization and role in the ecosystem, Marcel Dekker, New York. 2005: 27-37.

[4] Ezzouhri. Heavy metal tolerance of filamentous fungi isolated from polluted 
sites in Tangier, Morocco. African Journal of Microbiology Research. 3; 2009: 35-48.

[5] Warcup JH. The Soil-Plate Method for Isolation of Fungi from Soil. Nature. 166; 1950: 117-118.

[6] Nazareth S and Marbaniang T. Effect of heavy metals on cultural and morphological growth characteristics of halotolerant morphotypes. J Basic Microbiol. 48(5); 2008: 363-369.

[7] Suntornsuk W and Hang YD. Strain improvement of Rhizopus oryzae for production of $\mathrm{L}(+)$ lactic acid and glucoamylase. Lett. Appl.Microbiol. 19; 1994: 249-252.

[8] Anand $\mathrm{P}$ et al., Bioaccumulation ofcopper by Trichoderma viride, Bioresource Technology. 97; 2006: 101825.

[9] Rolhf FJ. Numerical taxonomy and multivariant analysis system. Version 2.02. Applied Biostatistics, New York. 1990

[10] Kumar S, Stecher G and Tamura K. MEGA7: Molecular Evolutionary Genetics Analysis Version 7.0 for Bigger Datasets. Mol Biol Evol. 33; 2016: 1870-1874.

[11] Pramod Kumar Mahish, Tiwari KL and Jadhav SK. Biodiversity of Fungi from
Lead Contaminated Industrial Waste Water and Tolerance of Lead Metal Ion by Dominant Fungi. Research Journal of Environmental Sciences. 9 (4); 2015: 159-168.

[12] Gadd GM. Interaction of fungi with toxic metals. New Phytol. 124; 1993: 2560.

[13] Raman Kumar et al., Potential of Some Fungal and Bacterial Species in Bioremediation of Heavy Metals. Journal of Nuclear Physics, Material Sciences, Radiation and Applications. 1(2); 2014: 213-223.

[14] Sharma GD et al., Isolation and Screening of Some Filamentous Fungi with Various Trace Metals. Indian journal of applied research. 4 (2); 2014: 7-12.

[15] Balsalobre L, De Siloniz MI, and Valderrama MJ. Occurance of yeasts in municipal wastes and their behavior in presence of cadmium copper and zinc. J.Basic. Microbio. 43; 2003: 185-193.

[16] Gayathri S. et al., Isolation of fungi from foundry soil for biomineralization. International Journal of Science, environment and Technology. 4(6); 2015:1581 - 1586.

[17] Padmasini Elango and Vijayakumar. Bioleaching of industrial waste foundry 
sand by Aspergillus sp. treated as

biofertilizer for the growth of herbal

plants - Coriandrum sativum.

International Journal of Advance

Research, Ideas and Innovations in

Technology. 4(2): 2018:1537-1540. 